\title{
Nonstandardization Based on Standardization
}

\author{
Gang MENG \\ Department of Architecture \\ Tongji University \\ Shanghai, P. R. China \\ e-mail: menggang@tongji.edu.cn
}

\begin{abstract}
Standardization has benefited the modern architecture as one part of industrialization technology. In the meantime it implies a restriction on individuality what is often highly praised by architects. We should look for a compromise between standardization and nonstandardization in architecture. This paper focuses on the methodology of diversification based on standardization technology. There are many typical cases from the past time till today.
\end{abstract}

\section{Keywords-standardization; industrialization; individuation}

\section{STANDARDIZATION}

"In the future the individual will be able to order from the warehouse the housing that is right for him."

-Walter Gropius, "Wohnhaus-Industrie", 1923

Gropius was so longsighted. At present even in some undeveloped areas Architectural Industrialization is not a newly-emerged thing anymore.

The economic committee of United Nations declares that Industrialization means continuity, organization, research \& development, standardization, integration and mechanization.

In view of the large-scale of this domain, this paper can't contain everything but only one typical element: standardization. Standardization is a foundational technique of architectural industrialization.

\section{TO STANDARDIZE, NOT TO BE STANDARDIZED}

\section{A. The Basic Characteristics of Standardization}

The greatest advantage of standardization is that it brings about easier and clearer technical communication in the cooperation among partners. In addition, training and specialization are in simpler demand. Therefore the cost and the time are reduced. Standardization can also achieve quality control. What must be emphasized is that the objects to be standardized cover not only products but also processes.

Accompanying the advantages, the disadvantages of standardization are evident as well. Sometimes standardizing also means less individuality even monotony.

Standardization indicates common lifestyles, common behaviors and common values in sociology. In other words, whom standardization fits for are standardized people.

\section{B. Primitive Standardization}

There were already some kinds of thoughts of standardization before industrial society came to the world (Fig. 1). They constantly involved basic building technology, aesthetic and politics. With standardization the relative advanced experiences could be transmitted easily and extensively. This was helpful for the backward areas above all.

A typical case is "Yingzao Fashi" (or "Ying-tsao-fa-shih", means Codes of Construction), a book of technical regulations published by the feudal royal government of the Northern Song Dynasty in China (Fig. 2). Through this book we can find the high achievements in standardization of architectural design in Song Dynasty. According to the different kinds of buildings, they worked out correspondingly a series of different measurements about the length and cross section of the structural members, including columns, frames, beams, rafters and etc., thus assuring both economy and durability. The book provides standard dimensional measurements for all the components. "Most of the book is documentation of the inherited traditions of craftsmen and architects passed down by word of mouth." (Wikipedia) "Yingzao Fashi" gave an impetus to traditional Chinese architecture. Craftsmen on different skill levels could acquire the same technology then kept buildings away from low-quality.

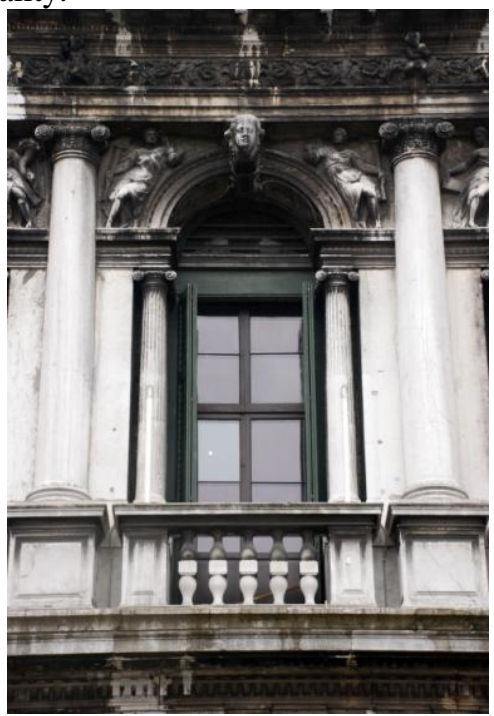

Figure 1. There were many typical standardized components in old western buildings, e.g. columns 

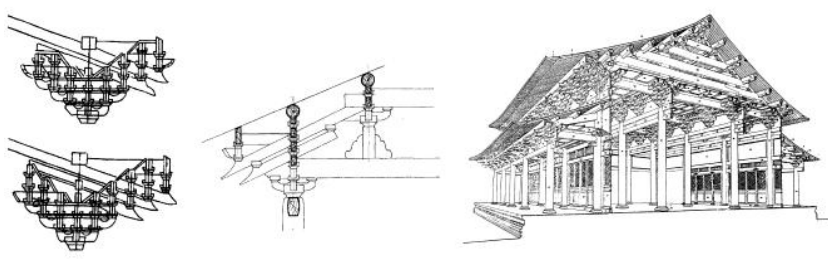

Figure 2. Pictures from "Yingzao Fashi", a book of technical regulations of traditional Chinese architecture

\section{Technical Facility and Restriction}

As what already mentioned above, standardization has been functioning as a technical facility as well as a restriction from its very beginning. "Yingzao Fashi" again, the buildings are under the controls of many mathematical formulae. They are often with hi-quality, hi-acceptability but less individuality.

But the instinctive individuality of the human kind has never disappeared. People are always fond of facilities but are sick of restrictions. As to standardization, what people prefer in essence is "to standardize" but not "to be standardized".

\section{The Standardized BUILDINGS IN MODERn TIME}

The assumption about architectural industrialization of Gropius encountered an opportune moment to be carried out in the post-war period. Common requirement became a motive force to standardization.

Prefabricated systems became almost universal by the mid-1960s in the countries of the former Soviet bloc. From the mid-1950s the Soviet Academy of Architecture insisted a sort of theory that architecture be practiced as a technical rather than aesthetic pursuit, "Architects into the Factories", as the reigning propaganda slogan. The trend of architecture industrialization even reached China which following the Soviet. Many countries, such as France, Denmark, Sweden, etc., had their own well-known standardized building system.

To achieve modularity architects must make choice of the basic unit at first. The ordinary basic units adopted by most architects include: (1) Modulor, the scale of harmonic measures; (2) Grids determined by particular numerals. (They were even applied in a lot of old buildings); (3) Rooms, usually with equipments; (4) Building components, mostly panel systems and frameworks (Fig. 3).

\section{NONSTANDARDIZATION WITH A STANDARDIZED FOUNDATION}

\section{A. Where the Restrictions Stay}

Standardization means somewhat simplification, some secondary factors that probably take important roles in other situations are neglected. Unfortunately individuality is among these disregarded factors because standardization only pays close attention to common requirements and mass production.

Figure 4 is an example that some rooms become not so reasonable because they must fit for a specific standardized shape.

\section{B. The Thoughts of Nonstandardization}

All the time design flexibility is one of the emphases that the architects concern about. Where there is a type of standardization, there is surely a type of nonstandardization. Nonstandardization implies a compromise, a balance and a coexistent relationship between individuation and standardization. Nonstandardization based on standardization is undoubtedly an advanced stage of standardization.

\section{NONSTANDARDIZATION IN PRACTICE}

There are really many compromise proposals for nonstandardization, in other words, for design flexibility.

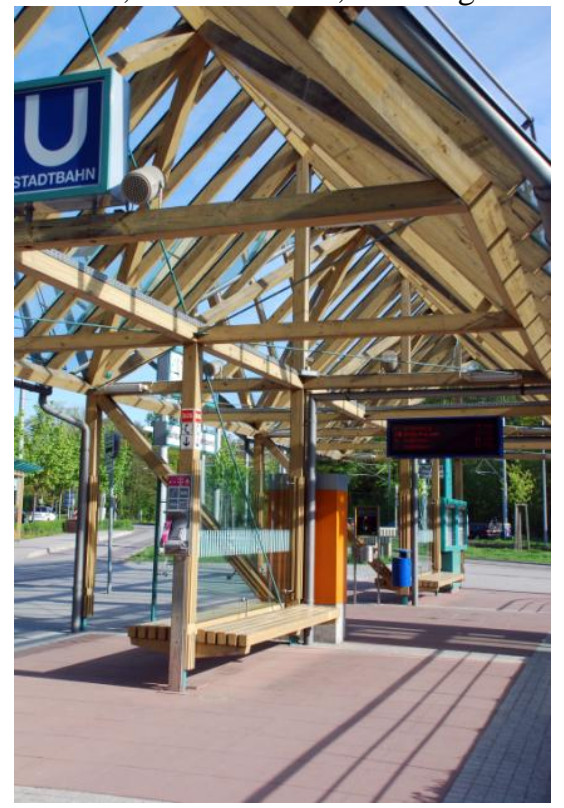

Figure 3. Standardized wood and steel frameworks

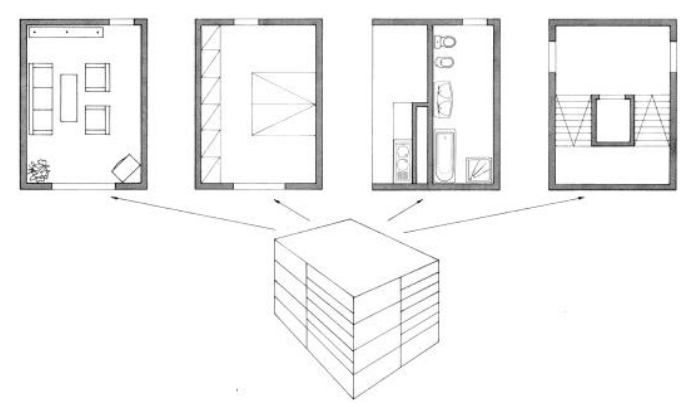

Figure 4. Standardized units sometime result in irrationalities if design losses its status (source: bauen industrialisiert, 1976)

\section{A. Various Options - Varied Types of Prefabricated Buildings}

Factory-built housing in America is a clear illustration. It contains four types of buildings that differ in assembly line, manufacture mode, quality control and the percentage of presite construction. The architects can make their selections after comprehending on-site environment, local codes and the customers' acquirement. Varied options act as a 
compensation for standardization to bring about more flexibility.

\section{B. The Separation of Standardized and Non-parts}

Most buildings can be divided into standardized parts and nonstandardized parts. The nonstandardized components bring individuality to the buildings (Fig. 5).

\section{C. $2 D$ and $3 D$ Composition}

The present professional education of architecture has given full consideration to construction technology, so some design techniques keep pace with the logic of industrialization and standardization. 2D and 3D composition have been obligatory courses for a long time in universities all over the world (Fig. 6).

\section{Individual Units}

In contrast with the concerns about the relation or logic among basic units, the basic units themselves can also be highly individualized to result in individual buildings. These individual units are often in uncomplicated arrangement.

So in a standardized project, what can be individualized are either the basic units or their arrangements. Individual units + simple arrangement (Fig. 7), or simple units + individual arrangement (Fig. 6), or individual units + individual arrangement are all appropriate selections.

\section{E. Appropriate Parameters}

Although we can hardly give a precise definition to "appropriate parameters", it is none the less very important to standardization. All building systems have their own series of parameters. The tendency of standardization and nonstandardization exist together in the series of parameters. The result is a kind of balance between them.

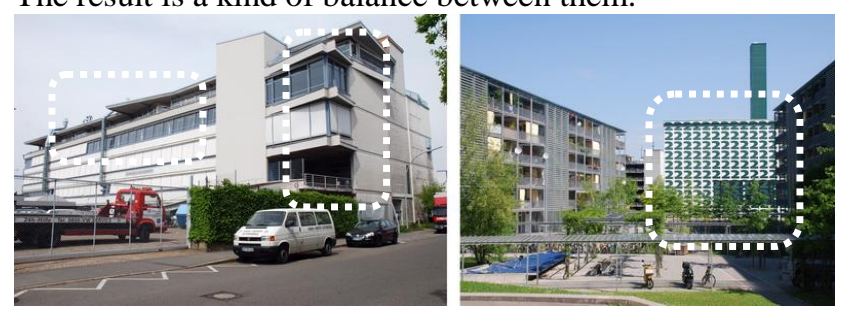

Figure 5. Nonstandardized parts bring individuality to the buildings
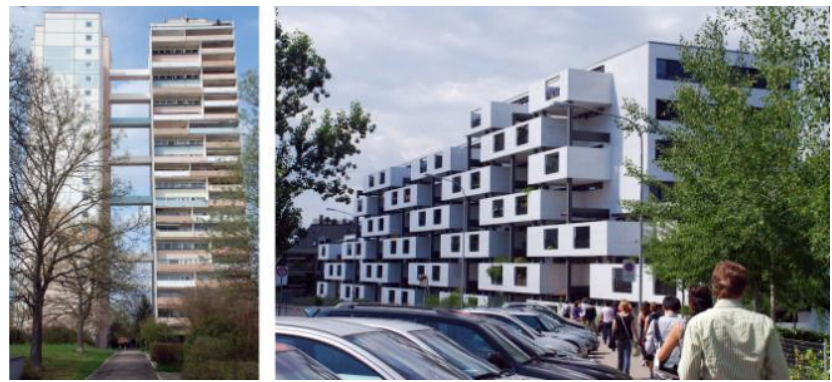

Figure 6. Composition behaves as a common design technique for diversification

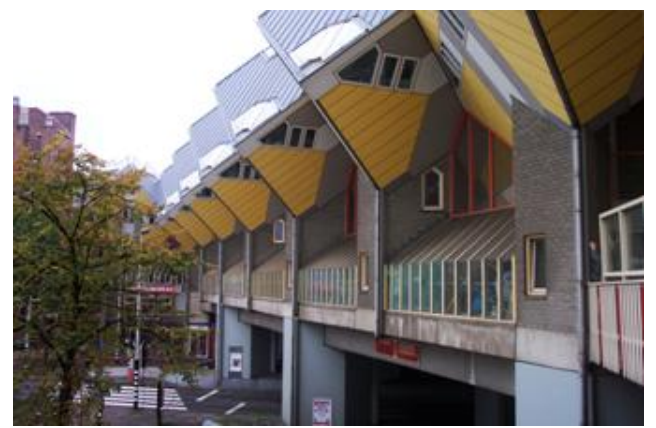

Figure 7. To individualize basic units is a simple method to make buildings individual

\section{F. "Architects Into the Factories" Again}

Differing from the former propaganda slogan, "architects into the factories" is meaningful to current standardized and nonstandardized architecture in other ways. It implies a predesign section before prefabrication. Architects should get wise to what happen in factories. Furthermore, architects can even create some individual components taking advantage of prefabrication. "Architects into the factories" means more initiatives for individuality.

A Vineyard, weinguts in Fläsch, in Switzerland (Fig. 8) is an appropriate footnote. The architects created an individual arrangement of the bricks. It reflects their comprehensive understanding of standardization and prefabrication technology.

\section{NONSTANDARDIZATION IN THE 21ST CENTURY}

In the new century the communications among different areas and various people become more and more convenient. Globalization is actuality no other than a new style of overall standardization. But in the meantime post-industrial society brings much more space to individuality. So we are partly standardized as well as partly differentiated. Either standardization or nonstandardization of architecture therefore has got to be put a new face on.

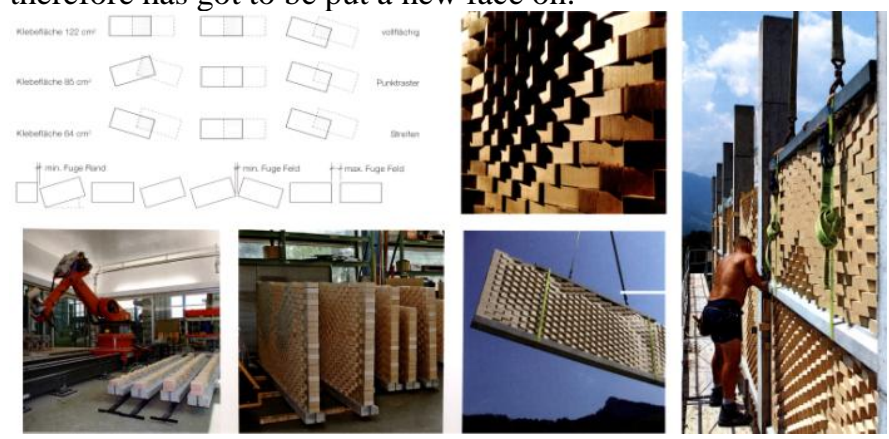

Figure 8. The manufacture of the wall of weinguts in Fläsch (source: elemente + systeme, 2008)

\section{A. Digitized Standardization and Nonstandardization}

To establish a digital library is obviously much easier than to build up a physical warehouse. With digital technology we can imagine a library of fully designed and engineered components that need only be assembled and 
minimally adapted in CAD files to create a great quantity of unique solutions with great efficiency. A well-known example is Greg Lynn's Embryological House.

\section{B. Prefabrication for Individual Buildings}

Early technique of standardization must comply with the common requirements. But at present, increasingly developed and efficient prefabrication technology also gains widespread popularity in many construction projects which have little to do with mass production. A well-known case is "Honeycomb Tube Architecture" (Japan). Standardization serves as an assistant of nonstandardization here.

\section{Standardized tool, Nonstandardized Design}

In a developed prefabrication system what can be standardized are not only building components but also some tools and abstract objects. The individuals' opinions can easier participate in the design process if there are mature standardized software platform. Contemporary manufacture technology expands the application of these platforms. In some cases the clients can even finish their unique design with standardized software, send them back to the factories and then they will get the products what they want (Fig. 9). Here only the software is standardized component. We should probably consider it as a new inspiration for the nonstandardized buildings.

Architectural standardization and prefabrication are renewed in the new century. While nonstandardized architecture, interestingly, has never separated from them. Even if there are inherent contradictions between them, standardization can provide strong supports to individuality of architecture.

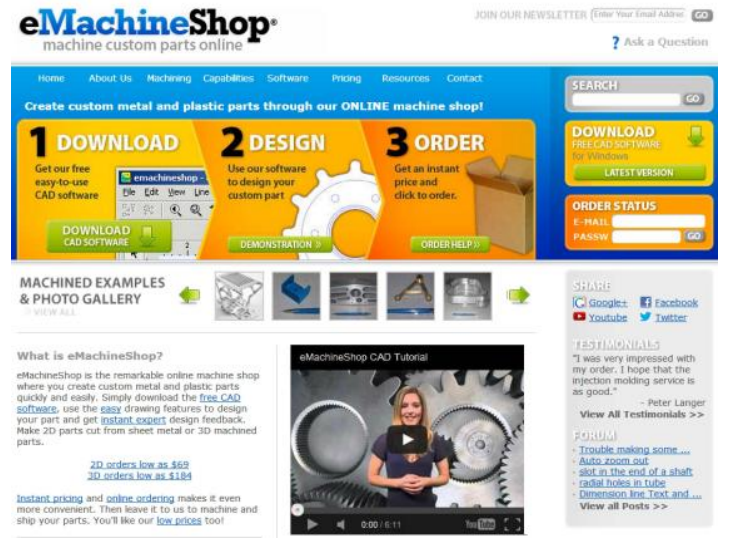

Figure 9. A webpage of an online factory enabling individual to design (source: from internet)

\section{REFERENCES}

[1] K. Junghanns. Das Haus für alle: zur Geschichte der Vorfertigung in Deutschland. Ernst \& Sohn, 1994.

[2] W. Förster. Wohnen im 20. und 21. Jahrhundert. Ernst, 2006.

[3] M. Anderson and P. Anderson. Prefab prototypes: site-specific design for offsite construction. Princeton Architectural Press, 2007.

[4] G. Staib, A. Dörrhöfer and M. Rosenthal. Elemente und Systeme: Modulares Bauen-Entwurf, Konstruktion, neue Technologien. Walter de Gruyter, 2008.

[5] Thanoon W. A., Peng L. W., Kadir M. R. A., et al. The essential characteristics of industrialised building system//International Conference on Industrialised Building Systems. 2003, 10: 11.

[6] Xin W., Xianjue L. Seeking the Difference in the Sino-west Culture From the Comparison of Ten Books on Architecture and Ying-tsaofa-shih[J]. Huazhong Architecture, 2001, 5: 001.

[7] HTA Association. Honeycomb Tube Architecture. Shinkenchiku-Sha, 2007.

[8] T. Koncz. Bauen industrialisiert. Bauverlag GMBH, 1976. 